\title{
Directions For the Study OF MASCULINity: BEYOND TOXICITY, EXPERIENCE, AND ALIENATION

\author{
Dylan A. Yaeger*
}

\begin{abstract}
The relationship between the law and masculinity has not been as thoroughly examined as the relationship between the law and feminism or, more generally, between the law and gender. Yet, the reach of masculinity stretches deep into the very fiber of the law. Masculinity has for too long served as an invisible bedrock on which the law founded both its substance and method. The struggle for formal equality during the last half century sought the elimination of the masculinist bias, but has only exposed the extent of the entrenchment. The popular idea is that the law exists in a removed and exalted position where it sits in judgement of a preexisting and fully formed masculinity. Indeed, much of the internal coherence of the law is premised on the integrity of the subject and the propagation of sexual difference. Thus, the law is precluded from acknowledging or engaging with its own productive power and vacuously characterizes itself as a neutral arbiter. Today, while significant changes occur in sex and sexuality, the study of masculinity appears theoretically stagnant.

Part I of this paper distinguishes between masculinity studies and the men's movement and explains the relationship of each to feminist theory. Part II looks at how the power of the law works and how masculinity studies is an effective tool to help understand how that power manifests and is employed. Part III examines the relationship between feminist legal theory and masculinity studies with a particular focus on two areas where I view masculinity studies as having successfully employed insights from feminist theory. Finally, Part IV considers four areas where I suggest masculinity studies could better incorporate certain insights from feminist theory, which would result in a more rigorous understanding of the relationship among power, masculinity, and law, and point masculinity studies in a more nuanced direction. To advance this critique, the paper analyzes underlying arguments that support the power of law based in classic liberal political theory. It employs recurrent critiques of the law, and of liberalism more generally, found in Feminist Legal Theory, Critical Race Theory, Queer Theory, and Critical Legal Studies to reveal the law as always already intertwined with masculinity.
\end{abstract}

\section{KEYWORDS}

Masculinity Studies, Feminist Theory, Gender, Sexual Difference, Brett Kavanaugh

\footnotetext{
* Visiting Scholar, Center for Changing Systems of Power at Stony Brook University.
} 


\section{CONTENTS}

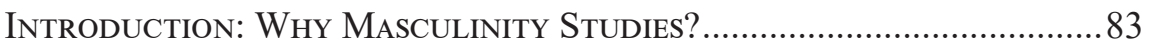

I. Masculinity Studies and the Men's Movement .................................83

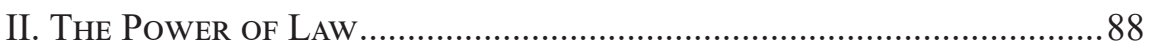

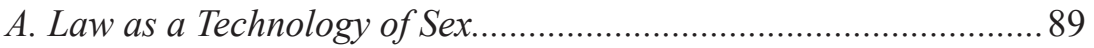

B. Ricci v. DeStefano: About Masculinity, Too .................................... 91

1. Defining Leadership: Assessment Mechanisms Bursting with Male Bias 92

2. A Vicious Cycle: Notions of Hegemonic Masculinity Leading to Perceived Powerlessness That then Result in Harmful Exhibitions of Masculinity... 96

3. Perspective Is Everything: Endorsing a Particular Kind of Masculinity by Pretending It Doesn't Exist ............................................................. 98

III. SUCCESSFUl Incorporation of Feminist Theory InSIGHTS............. 100

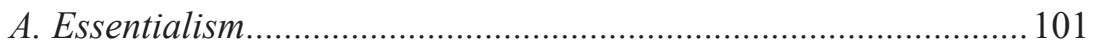

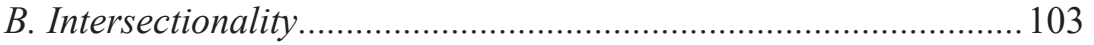

IV. OPPORTUNities FOR INCORPORATING Feminist Theory InsightS.....106

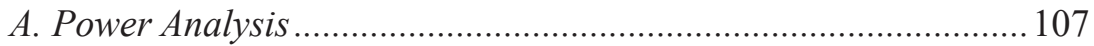

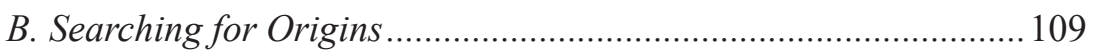

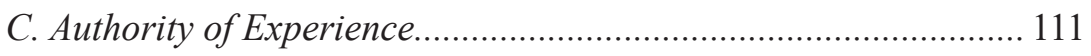

D. Political Nature of Sexual Difference .......................................... 113 


\section{InTRODUCTION: Why Masculinity StUdies?}

Why study masculinity in the first place? Why study masculinity and law? Historically, the masculine subject position has been the default. It was not until the mid-1990s that scholars even decided that men also had a gender. To the surprise of many, not only were men also gendered, but so too were structures, institutions, relationships, and discourses. The invisible but ever-present subject (never the object) refused to be named, thus rendering male domination even more insidious. Since then, a rich history of scholarship has emerged dealing with the relationship between masculinity and law, from varied perspectives and ideological viewpoints. ${ }^{1}$ A substantial component of masculinity studies consists of using feminist and queer theory to explore variations and dynamics among masculinities. Indeed, feminist theory has provided the foundation, both analytically, theoretically, and historically, upon which masculinity studies is based. Yet, the critical study of masculinity within a legal context remains woefully marginal to mainstream legal study.

While feminism has had a discernable impact on history, politics, philosophy, sociology, economics, and law, masculinity is most marked by its absence, its invisibility. ${ }^{2}$ Masculinity is simultaneously nowhere and everywhere; as Richard Dyer has commented, it is a bit like air: you breathe it in all the time, but you aren't aware of it much. ${ }^{3}$ In much the same way that heterosexuality, in contrast to homosexuality, is constructed as not being historically contingent-masculinity, until recently, has been thought of as a more self-evident, natural, and stable category than femininity. The overseeing and invisible subject — as de Beauvoir has called masculinity ${ }^{4}$ - however, is now the object of study.

Part I of this paper distinguishes between masculinity studies and the men's movement and explains the relationship of each to feminist theory. Part II looks at how the power of the law works and how masculinity studies is an effective tool to help understand how that power manifests and is employed. Part III examines the relationship between feminist legal theory and masculinity studies with a particular focus on two areas where I view masculinity studies as having successfully employed insights from feminist theory. Finally, Part IV considers four areas where I suggest masculinity studies could better incorporate certain insights from feminist theory, which would result in a more rigorous understanding of the relationship between power, masculinity, and law, and point masculinity studies in a more nuanced direction.

\section{Masculinity Studies And the Men's Movement}

The study of masculinity has taken two distinct, and often antagonistic, trajectories: masculinity studies and the men's movement. While both assert that masculinity

1 See, e.g., R.W. Connell, Masculinities (2005); Jack S. Kahn, An Introduction to Masculinities (2009); Michael S. Kimmel, The Gendered Society (2000); Richard Collier, Men, LaW and Gender: Essays on the 'Man' of LaW (2010).

2 Richard Collier, Masculinity, LaW and the Family 4 (1995).

3 Richard Dyer, Male Sexuality in the Media, in The Sexuality of Men (Andy Metcalf \& Martin Humphries eds., 1985).

4 Simone de Beauvoir, The Second Sex (1972). 
is a particular phenomenon that should be investigated in its own right, they emerged out of very different political arenas. Masculinity studies emerged from a foundation of feminist theory, while at the same time being a response to the men's movement-a political undertaking that began in the 1980s to "reclaim manhood" from the purported emasculating effects of industrial society, feminism, and consumer culture. ${ }^{5}$ While the men's movement is quite variegated, one thread that runs through its various manifestations is the search for an essence of masculinity. In contrast to the men's movement's essentialism, masculinity studies generally views manliness and masculinity itself as social constructions and "situate[s] masculinities as objects of study on par with femininities, instead of elevating them to universal norms." $"$

Masculinity studies is grounded in the idea of finding a space beyond patriarchy. Examining the history of the critical study of masculinity reveals this emancipatory nature; the connection between masculinity studies and freedom. When considered through either an experiential or theoretical lens, masculinity both restrains and shepherds male behavior, thereby limiting an individual's freedom. Like feminist studies, masculinity studies strives to break free from the confines of patriarchy. In addition, and in contrast to the emphasis on freedom, masculinity studies has focused on identity and practice, by exposing what masculinities are and how they function. ${ }^{7}$ In this way, masculinity studies is an inquiry into the "nature" of masculinity, but it also, in some ways, is a response to the men's movement and the "crisis" in masculinity which purportedly created that movement.

Examining the way in which masculinity studies emerged as a response to the men's movement highlights an inherent tension that continues to shape the discipline today. In many ways, feminism led to two ideologically opposite gendered projects (the men's movement and masculinity studies). Masculinity studies is cognizant of the fact that the men's movement was also a response to feminism and is thus, in some sense, compelled to address its relationship to the men's movement or at least the concerns of the men's movement. The tension results from masculinity studies needing to engage with the often xenophobic and patriarchal men's movement (e.g., issues of men's perceived powerlessness and emasculation) while respecting the analytic traditions of feminist theory. So, in addition to the overarching agenda of dismantling patriarchy, masculinity studies responds to the men's movement by attempting to speak to the experiential lives of men (which is what the men's movement maintains it does) without, crucially, suggesting that masculinity contains an essence. Whereas the analytical tools

As Robert Bly suggests in the opening lines of his quintessential men's movement book, Iron John: A Book About Men: "We are living at an important and fruitful moment now, for it is clear to men that the images of adult manhood given by popular culture are worn out; a man can no longer depend on them. By the time a man is thirty-five he knows that the images of the right man, the tough man, the true man which he received in high school do not work in life. Such a man is open to new visions of what a man is or could be.” Robert Bly, Iron John: A Book About Men ix (1990).

6 Harry Brod, Introduction: Themes and Theses of Men's Studies, in THE MAKING OF Masculinities: The New Men's Studies 2 (1987).

7 Nancy E. Dowd, Masculinities and Feminist Legal Theory, 23 Wis. J.L. GeNDER \& SoC'y 209 (2008). 
borrowed from feminist (and queer) theory tend to favor more macro issues-like the existence of gender categories and both epistemological and ontological inquiries into sexual difference and subjectivity-masculinity studies must also respond to the more micro, deep-seated experiential alienation felt by particular men. Indeed, this micro/macro tension within masculinity studies continues to seriously affect the level of nuance and sophistication brought to the critical study of gender today. In addition, the clear need to eradicate the explicit sexism, misogyny, transphobia, and "toxic masculinity" ubiquitous in our present culture - issues that, decades ago, the more optimistic among us thought would no longer exist in 2020-renders the more macro issues less seemingly urgent.

In its early days, masculinity studies, like the men's movement, appeared relatively self-serving, portraying men as victims of the social construction of masculinity. ${ }^{8}$ Masculinity studies represents, simultaneously, a struggle against patriarchy and a response to an experiential crisis felt by many men. In this respect, masculinity studies perpetually searches for a balance between engagement with larger structural issues that perpetuate patriarchy and with more specific experiential conditions which lead to individual men feeling alienated and masculinity as a whole being characterized as in crisis.

The way identity politics have played out is important in this context because of the impact they have had on masculinity. Feminism has provided the theoretical framework from which to think more profoundly about the role of masculinity within patriarchy and, in some sense, led to the creation of the men's movement, a movement premised on masculinity being in crisis. That feminism has provoked these two hostile (to one another) reactions illustrates how relational identities are and how neither feminine nor masculine identities exist in a vacuum: "feminisms exist precisely because masculine power regimes exist; feminisms are a point of dynamic resistance, providing their own distinct knowledges, truths, practices, not merely as a point of opposition but by offering ontological possibilities through pronouncing and identifying distinct epistemologies." 9 Thus, feminism, while providing the analytical and theoretical foundation for masculinity studies, has undermined male supremacy and contributed to the "crisis" in masculinity.

The men's movement began in the late 1980s to revision and reclaim manhood. At the same time, the burden of the normative constraints of masculinity on men began to intensify. What is distinctive about the "crisis" from the perspective of the men's movement is that it resulted from a tension between men who were still expected to be "at the helm" in a culture that now expected them to be reflective about their masculinity. ${ }^{10}$ (In contrast, to better contextually comprehend the presence of the crisis, legal scholar Nancy Dowd has highlighted how the feeling of

\footnotetext{
8 Stephen M. Whitehead, Men and Masculinities: Key Themes and New Directions 48 (2002) (describing Susan Faludi's argument "that modern man has been 'betrayed' by a combination of factors, notably a sexist consumer culture that commodifies and objectifies the male; the loss of economic authority; the weakening and reshaping of men's relationship to the world of work; the public exposure of dominant notions of masculinity to ridicule and censure; and the failure of men, as a gender group, to 'rebel' against their emasculization by 'the culture."').

$9 \quad$ Id. at 107.

$10 \quad$ Id. at 48 .
} 
crisis is itself a characteristic of masculinity and has often been used as a rationale for reinterpreting masculinity in a way that reconstitutes patriarchy. $)^{11}$

In response to the perceived crisis, the men's movement sought to identify and reinstitute a singular, unifying essence of masculinity. In contrast, masculinity studies stresses that "masculinity should be seen as always ambivalent, always complicated, always dependent on the exigencies of personal and institutional power." 12 The building blocks of masculinity studies derive from the same ambivalent crises of identities and paradoxes that propelled the rise of the men's movement. While the men's movement addresses these crises by resorting to an essentialized understanding of what it means to be a man in today's world, masculinity studies recognizes the inherent struggles and dichotomies which plague any attempt to bound masculinity.

In the context of the men's movement, masculine identity is very much about loss and lacking. ${ }^{13}$ Thus, the men's movement has emphasized the theme of "retrieval" as being critical, psychologically and tangibly, if masculinity is to become whole again. Robert Bly, one of the progenitors of the men's movement, argued that such retrieval can be accomplished once men get in touch with their "true selves" by bonding with other men. Bly suggested that a significant part of adult male pain originates from the lack of a relationship between fathers and sons and that feminism was to blame for the shift in power that left masculinity in crisis. The pride and stoicism prevalent in earlier cultural tropes of ideal manhood and found in popular representations like John Wayne or Clint Eastwood have given way to a defensive masculinity that views itself as constantly under threat and wallows in self-pity. Men, the traditional genderless masters of the public/political arena, have been branded in certain circles as politically problematic, gendered subjects. ${ }^{14}$

$11 \quad$ See Dowd, supra note 7, at 208. Further, the men's movement can be distinguished from other rights' movements due to the privilege held by the group seeking recognition. While other rights' movements could point to an oppressor against whom to struggle, not only did white men lack an oppressor, but they themselves were already portrayed as the oppressor of others. This characterization — of men struggling against the requirement that they relinquish a degree of power while continuing to bear the full burden of prior expectations - utilizes a one-dimensional understanding of power that falls into the intuitive trap of thinking of power solely in a judicial sense. The suggestion is that male identity is "in crisis" because some amount of power has been taken away from men; a suggestion that assumes that power is a commodity that transfers between groups and individuals. The unidirectional understanding perpetuates an oppressor-victim dualism fundamental to liberalism, and fails to account for the productive, identity-forming and knowledge-creating component of power. Furthermore, the notion that something is "off" about the way in which gender relations are structured now-as opposed to at some earlier, utopic, more natural time; a pre-feminism time - both suggests that a natural gender order does exist and takes a normative position on what that gender order should look like.

12 Maurice Berger et al., Introduction to Constructing Masculinities 3 (Berger, Wallis, \& Watson eds., 1995) (noting the shared conclusion of the collected essays).

13 Fidelma Ashe, The New Politics of Masculinity: Men, Power and Resistance 1 (2007) ("the key terms that have emerged in popular discourse about the plight of the modern man have been 'crisis', 'loss' and 'change'").

14 Id. 
Certain cultural feminist critiques view normative masculinity as a constitutive element of the inequity, violence, and degradation that characterize white, western, capitalist culture. By critiquing the normative male, feminists have contributed to the disavowal of traditional attributes of manhood such as "self-direction and discipline" and "toughness and autonomy," and have suggested they be replaced by "soft" behavioral traits such as emotional sensitivity and vulnerability. Traits traditionally attributed to women and children are now being ascribed to men. In contrast, the men's movement has sought to find an ahistorical, transcultural, and almost mythological definition of full-fledged masculinity. This goal of the men's movement, believers argue, has been supplanted, eroded, covered over, and destroyed by the tandem of feminism and "the mode of industrial domination." 15 According to men's movement adherents, industrial society and feminism work complicitly to tame the archetypal male; they are not separate and distinct realms, but by-products of one another-equally guilty perpetrators of the castration of the modern man. ${ }^{16}$

Notwithstanding the ostensibly progressive agenda of masculinity studiesparticularly in contrast to the men's movement - it undoubtedly has had multiple effects. Masculinity studies has tended to favor a critique of masculinity itself, as opposed to a critique of gender categories. And it has tended to favor a relatively narrow critique of patriarchy, without challenging the overarching political and social structures that facilitate patriarchy. While masculinity studies has tended to view itself as emancipatory, in many ways, it simply reifies established ideas about sexual difference. Thus, masculinity studies is often in danger of falling into essentialist rabbit holes and privileging experience over theoretical inquiry (and over a comprehensive critique of the relationship between masculinity and power). This relationship - between masculinity and power-has always been at the forefront of how the law engages with patriarchy.

Perhaps most important when thinking about the direction of masculinity studies, particularly in the context of its relationship to the law and with both feminist theory and the men's movement, is the role that power has in masculinity studies. The issue of power has been front and center in both the genesis of the men's movement (arguably the "crisis" in masculinity is most concisely described as the forced relinquishing of power by men and the resulting psycho-social impact) and in feminist theory. Thus, it is no surprise that power (and the power of law) is also a critical issue for masculinity studies. Significantly, though, many of the insights regarding power that were foregrounded in feminist theory either

5 Bly, supra note 5, at 98.

16 Yet, while this occurs there is a sensitive father emerging, struggling and advocating for the right to be the primary caregiver for his children, and "burdened" by having to be his household's primary breadwinner. The father's rights' movement is central to the men's movement, and intricately tied to the liberal conception of the self at the heart of this critique, in the sense that traditional notions of fatherhood have been tied to an individualized notion of autonomy, which, in turn, was associated with a set of beliefs about the nature of masculinity. The evolving nature of the role of the father is the archetypal representation of the crisis and tension in masculinity. When thinking about fathers' rights or the men's movements, or the large swaths of alienated white, rural, working-class men in the 2016 election, the so-called solution cannot be either the outright dismissal of the position nor can it be the full embrace of their experience. It is equally unfeasible to either embrace the experience as true or to dismiss it as untrue. 
have not received the attention they should or have been too easily dismissed because of what are thought to be more pressing concerns (e.g., dealing with explicit sexism, discrimination, and misogyny). Ultimately, I am suggesting that a more robust understanding of masculinity requires a return to an engagement with issues surrounding power, notwithstanding such concerns. Absent real engagement with issues of power, today's problems will be exacerbated rather than solved. Masculinity studies seeks to change the misogynistic and sexist behavior of men by highlighting the restrictive and unhealthy components of masculinity. But while it is tempting to simply argue against the naturalness of how masculinity is presented in today's popular social and cultural world, real growth will only occur if a more robust engagement with issues of power is undertaken.

\section{THE POWER OF LAW}

Masculinity studies places great emphasis on issues of power. Indeed, as MacKinnon observed, if masculinity is anything at all it is a system of power. ${ }^{17}$ Much work has been done examining the functioning of power, but power has been considered less as a discursive force and more as the foundation of patriarchy. Power, from the perspective of the law, is often considered as a force to regulate or redistribute, but the law ought to spend more time self-consciously reflecting on the impact of its own power. The law serves as a technology of sex ${ }^{18}$ that reifies masculinity and sexual difference by constructing masculinity as a biological given rather than a discursive category that is part of a neoliberal political agenda. Nevertheless, the mainstream understanding of the relationship between the law and masculinity focuses on how the law is needed to control and rein in masculinity. The notion that the law is actually privileging and perpetuating a particular form of masculinity is not taken seriously in mainstream legal analysis. ${ }^{19}$ Masculinity studies, on the other hand, opens the door to a view of the law as a contributor to, if not outright creator of, existing power relations and not simply a regulator of pre-existing ones.

17 Male dominance "is perhaps the most pervasive and tenacious system of power in history." Catharine A. Mackinnon, Feminism, Marxism, Method and the State: Toward Feminist Jurisprudence, 8(4) Signs 638 (1983).

18 By "technology of sex"- borrowing here from Teresa de Lauretis, The Technology of Gender, in TeCHNOLOGIES OF GeNDER (1987) - I mean the way in which the law acts as a creator of norms, standards, rules, techniques, and discourses that govern-in a specific way that emphasizes a particular relationship between power, truth, and knowledgehow we think about sex.

19 It is, though, considered very seriously in masculinities studies. An example of where this dynamic plays out is in criminal law where a "heat of passion" defense reduces a charge of murder to manslaughter, and "heat of passion" involves "men killing women who have bruised their masculine esteem by denigrating their sexual prowess or becoming involved with other partners." As McGinley and Cooper have pointed out "it seems that defending one's masculinity against women is reasonable enough to cut years off your sentence. Here, then is an example of law mirroring, if not reinforcing or even creating, a culture in which we assume "boys will be boys." Ann C. McGinley \& Frank Rudy Cooper, Identities Cubed: Perspectives on Multidimensional Masculinities Theory, 13 Nev. L.J. 326, 338 (2013). 


\section{A. LaW as a TeChNology of SeX}

Masculinity studies allows for a view of the law as a contributor to what masculinity itself is, rather than just a regulator of a pre-existent masculinity. I use the very passive language "allows for" (as opposed to saying that masculinity studies, in fact, is doing something) because while the discursive space is available to masculinity studies due to its theoretical foundations, the analysis of power (and specifically the way the power of the law is exercised) it employs is often lacking. While feminist theory was interested in thinking about redistributing power and, significantly, about how power operated, masculinity studies often acts as if the "how" question already has been answered, and the only remaining issue is redistribution. Like mainstream civil rights advocates, masculinity studies tends to be preoccupied with combating patriarchy through legalistic means, as opposed to thinking about power as relational, productive, and, crucially, not solely held by certain individuals like a commodity. Thus, while the ideas about power discussed above, born in feminist legal theory, have found application in masculinity studies, each has been embraced to varying degrees.

According to a conventional understanding of how power manifests, law is prohibitive and repressive; it exerts its power primarily through domination. Particularly in U.S. Constitutional law, where the charter is conceived of as containing negative liberty rights that protect citizens from the government stepping into their private lives, as opposed to a source of positive liberty rights, the law rarely conceives of its power as productive. If, in contrast, power actually manifests in the creation of norms and the productive deployment of disciplinary techniques, then the juridical power of law is easily dismissed as a residual accessory to the predominant powers of modernity. Equating the power of law exclusively with repression fails to account for all the ways that the law's power functions productively to create norms and form cultures - which are the predominant powers of modernity - and "excludes a richer consideration of the law's constitutive capacities. ${ }^{20}$ Due to the combination of repressive and productive powers, the law occupies a unique position with respect to the reproduction of gender relations in our social environment.

To the extent that the law attempts to influence a society, it identifies qualities that can be scaled up from a model individual, ${ }^{21}$ and the society created reflects the qualities that the law has validated and perpetuated in the model individual. Of note, the so-called model individual evidently exists within a patriarchy and, thus, any scaling up from such individual perpetuates a phallocentric culture. Thus, the law creates a structure for society based on an already-adopted theoretical position on the nature of sexual difference and the characteristics of an individual subject that is both formed and dominated by the law. In this way, the law can never be separated from its own understanding of sexual difference, which is forever intertwined with the model of the world the law seeks to create. Therefore, the law is a "technology of sex" in that it is a creator of techniques, norms, standards, rules, and discourses that dominate and govern the way society understands sex and gender.

20 Ben Golder \& Peter Fitzpatrick, Foucault's Law 17 (2009).

21 Saul Levmore \& Martha C. Nussbaum, Introduction to AMERICAN GuY: MasCulinity IN LaW and Literature 1 (Saul Levmore \& Martha C. Nussbaum eds., 2014). 
In the words of James Boyd White, the law is:

not merely a system of rules (or rules and principles), or reducible to policy choices or class interests, but it is rather what I call a language, by which I do not mean just a set of terms and locutions, but habits of mind and expectations - what might also be called a culture. It is an enormously rich and complex system of thought and expression, of social definitions and practices, which can be learned and mastered, modified or preserved, by the individual mind. The law makes a world. ${ }^{22}$

The law is perpetually invested in re-articulating its own world view, resulting in the "creeping hegemony of the legal order." ${ }^{33}$ This creeping hegemony matters because it affects the way masculinity is thought about. Indeed, once coopted by the legal order, the study of masculinity becomes another tool by which the law can propagate - implicitly and explicitly, intentionally and unconsciously - a particular form of masculinity and, in the process, further entrench sexual difference. The power of the law, therefore, is continually reinforcing itself, re-articulating its own worldview, and weighing on society until the perspective it is advocating has been internalized. As certain scholars have highlighted, the law operates in its own realm, yet it also plays a role in power struggles over cultural dominance. ${ }^{24}$

If, on the other hand, the power of the law was actually recognized to be productive (and if sex was considered fluid and dynamic), then it would be accepted that the law had an impact on sexual difference, and the legal order would be accountable in some sense. But, since sexual difference is predominantly thought about as binaried and natural, the legal order is rarely considered to have an impact on sexual difference and is not held responsible-how could the law (something so conceptual) actually affect something like sexual difference (something so corporeal)? The law's reasoning, though, is teleological: in order to not be held responsible for the way masculinity manifests in the world, the law needs to believe in both a particular conception of the power of law and a particular idea of sexual difference. The law claims to not have a productive power by pointing to the naturalness of sexual difference which is, from the law's perspective, clearly beyond the influence of the law. The reluctance to take accountability compels the law to maintain essentialist understandings of masculinity which reinforce its conception of sexual difference, and the cycle begins again. Therefore, the law serves as a technology of sex that perpetuates a hegemonic masculinity, yet it fails to take any culpability when that masculinity manifests in undesirable but inevitable ways. Rather than being presented as fractured and disjointed social constructs, sexual categories are presented as resilient and stable, harking back to dated notions of a stable subject and suggesting that, through much trial and error, masculinity will one day find its essence.

\footnotetext{
James Boyd White, The Legal Imagination xiii (abridged version 1985).

Carol Smart, Feminism and the Power of Law 5 (1989).

24 Lisa Duggan \& Nan D. Hunter, Sex Wars: Sexual Dissent and Political Culture 206 (2006).
} 


\section{B. Ricci V. DeStefano: About Masculinity, Too}

The 2009 Supreme Court decision in Ricci v. DeStefano, ${ }^{25}$ ruling on a reverse discrimination (discrimination against traditionally advantaged groups) claim against the City of New Haven, and the subsequent Senate confirmation hearing for then-Judge Sotomayor, provides an example of how the law utilizes its power to creates norms with a scope far greater than the explicit subject matter of any one particular case. In Ricci, white firefighters scored higher than their Black and Latino counterparts on written tests for promotion. Given the disparities in exam scores, the City's civil service board declined to certify the results. The suit alleged that, by discarding the test results, the City discriminated against the plaintiffs based on their race, in violation of both Title VII of the Civil Rights Act of 1964 and the Equal Protection Clause of the Fourteenth Amendment.

The Court concluded that race-based action like that of the City is impermissible under Title VII unless the employer can demonstrate that, had it not taken the action, it would have been liable under the disparate-impact statute. According to the Court, the City's race-based rejection of the test results could not satisfy the strong-basis-in-evidence standard. The Court found that, because the tests were job related, the City lacked sufficient evidence that it would have been liable for disparate impact had it certified the test results. While the Court's opinion explicitly focuses on race, the decision and the spectacle that ensued when two of the plaintiffs testified at the Sotomayor confirmation hearing, ${ }^{26}$ which adopted the image of the "firefighter hero" 27 as a white male, feature elements that would benefit from being viewed from a perspective informed by gender.

Applying a masculinity studies lens to Ricci reveals the extent to which particular conceptions of masculinity are ingrained in our culture in three main ways. (Counterintuitively, the insidiousness of hegemonic masculinity is often most apparent when gender issues are not being addressed directly.) First, Ricci highlights the complexities and biases that permeate assessment mechanisms and, more specifically, how internalized, gendered ideas inform the selection of relevant performance criteria. Second, Ricci perpetuates a notion of hegemonic masculinity that ultimately results in feelings of powerlessness and inadequacy among young men, who are compelled to prove their manhood in harmful ways. Third, Ricci exemplifies how the law decides to see a case from one perspective (the aggrieved white and sometimes Latino firefighter) that both privileges and endorses a specific notion of hegemonic masculinity.

$25 \quad$ Ricci v. DeStefano, 557 U.S. 557 (2009).

26 Judge Sotomayor was a member of the Second Circuit panel whose affirmance of a district court's decision had been appealed. See Ricci v. DeStefano, 264 Fed. Appx. 106 (2d Cir. 2008).

27 The decision has been described as an "ahistorical, acontextual victory to the plaintiffpetitioners [who] engaged in the construction of the firefighter hero as white (and on one occasion, Hispanic) and male." Ann C. McGinley, Ricci v. DeStefano: A Masculinities Theory Analysis, 33 HaRv. J. L. \& GeNDER 581, 584 (2010). 


\section{Defining Leadership: Assessment Mechanisms Bursting with Male Bias}

The Ricci decision provides a classic example of the law employing its power in a norm-creating, non-juridical manner. The criteria believed to be determinative of character and leadership, which have been internalized by the law and which are endorsed by the Court, exhibit a substantial male bias that renders leadership and "character" more accessible to those who perform masculinity in a conventional manner. At the heart of the Ricci decision and the subsequent questioning of two of the plaintiffs by the Senate Judiciary Committee was the accuracy and fairness of the mechanism by which the City assessed fitness for job promotion. ${ }^{28}$

The Committee Republicans (seven white men) invited plaintiffs Frank Ricci and Ben Vargas to testify. Their questioning touched upon the validity of the firefighter promotion exams. Ricci and Vargas repeatedly noted that the tests were "unquestionably job-related" and stressed their fairness. ${ }^{29}$ When asked why the tests were important Ricci answered "over 100 firefighters die in the line of duty each year, an additional 80,000 are injured. You need to have a command of the knowledge in order to make command decisions.... Experience is the best teacher, but only a fool learns in that school alone." ${ }^{30}$

The opinion, penned by Justice Kennedy, includes an excerpt of a statement by Ricci: "I don't even know if I made it [b]ut the people who passed should be promoted. When your life's on the line, second best may not be good enough." 31 The second sentence aligns with the Court's focus on the job-relatedness of the tests, but Kennedy's choice to include the first sentence ("I don't know if I made it. . ..") is curious. ${ }^{32}$ Here, he highlights Ricci's integrity, picking an example of the firefighter's magnanimity - he brought this suit not out of self-interest, but because he cares about the profession! The quote does not speak to the value of the

28 The Court ruled on this issue stating: "There is no genuine dispute that the examinations were job related and consistent with business necessity. The City's assertions to the contrary are "blatantly contradicted by the record." DeStefano, 577 U.S. at 587-88. The Court also cited evidence that showed the opposite - expert testimony that the written exams were not the best way to determine leadership and command presence- the skills necessary to be a good fire officer. $I d$. at 571-72.

29 The respondents in Ricci did not argue that the test was not "job-related." This was a distortion of the issue by the plaintiffs and the questioning Senators. As explained in Justice Ginsburg's dissent, the relevant inquiry is whether there was a more appropriate way to evaluate the relevant skills in applicants and identify the best candidates, not whether the test was job-related. 577 U.S. at 635 (citing Robinson v. Lorillard Corp., 444 F. 2d 791, 798, n. 7 (4th Cir. 1971) ("It should go without saying that a practice is hardly 'necessary' if an alternative practice better effectuates its intended purpose or is equally effective but less discriminatory."); Boston Chapter, NAACP v. Beecher, 504 F. 2d 1017 , 1021-1022 (1st Cir. 1974) ("A test fashioned from materials pertaining to the job . . . superficially may seem job-related. But what is at issue is whether it demonstrably selects people who will perform better the required on-the-job behaviors.")). Focusing on job-relatedness eliminates the "business necessity" component of the standard. Id. at 636 (citing Lanning v. Southeastern Pa. Transp. Auth., 181 F. 3d 478, 489 (3d Cir. 1999)).

30 Transcript of Judge Sonia Sotomayor Confirmation Hearings (July 17, 2009), nytimes. com/2009/07/16/us/politics/16confirm-text.html.

31577 U.S. at 568.

32 Id. 
assessment mechanism, but rather to Ricci's character-something that, due to its inclusion, we can assume Kennedy found relevant.

The worth of the assessment mechanism can be considered in numerous ways: on the one hand, whether the assessment mechanism in question was discriminatory ${ }^{33}$ on the other, how as a society we assess character and leadership. The Court's conflation of character and competence is exacerbated by the flimsiness of our ways to measure character-as McGinley points out: "No one questioned whether the test results would necessarily locate the persons who would be best for the jobs. All equated test results with merit and with hard work. ${ }^{34}$ Indeed, Kennedy noted expert testimony regarding the inadequacy of written tests to assess people, ${ }^{35}$ but punted, explaining that the case was concerned only with whether the City could certify the test results. ${ }^{36}$

Almost as if taking a cue from Kennedy's highlighting of character, most of the plaintiff firefighters' time during the confirmation hearing was spent describing the character needed to fight fires. They spoke about fairness and that they had "played by the rules." They spoke about hard work and sacrifices. They spoke about the danger and complexity of their jobs. They spoke about their roles as the heads of their families, as breadwinners, fathers. Senator Lindsey Graham told Ricci that he would "want [him] to come to my house if it was on fire." Ricci and Vargas were repeatedly thanked for their service, held up as exemplar members of their community, and commended for their courage.

That emphasis on the ways to determine character was on display again when then-Judge Brett Kavanaugh testified before the Senate Judiciary Committee at his confirmation hearing in October 2018. Like the firefighters, much of Kavanaugh's testimony, ${ }^{37}$ focused on his character; Ricci, Vargas, and Kavanaugh all testified

33 The Court addressed the question of whether the promotion test was discriminatory: "Respondents thought about promotion qualifications and relevant experience in neutral ways. They were careful to ensure broad racial participation in the design of the test itself and its administration. As we have discussed at length, the process was open and fair." Id. at 592-93. As Justice Ginsburg explained in her dissent, a finding of "good intent or the absence of discriminatory intent" is not relevant to a Title VII analysis; what must be examined is the test's "business necessity." Id. at 621-22. The disparate treatment of applicants was not an issue in Ricci. No argument was made that there was discriminatory intent or disparate impact.

34 McGinley, supra note 27, at 618.

35 "Janet Helms ... declined to review the examinations and told the CSB that, as a society, 'we need to develop a new way of assessing people.' That task was beyond the reach of the CSB, which was concerned with the adequacy of the test results before it." 577 U.S. at 592.

36 Kennedy frames the case as one of determining the legality of the race-based action performed by the city (whether the city's actions in discarding the test results violated Title VII), but this is straightforward legal abstraction. The decision is cloaked in the difference between disparate treatment and disparate impact, but the case is fundamentally about assessing people and the validity of the assessment mechanisms in question. Helms' determination that "we need new ways to assess people in society" is beyond the scope of the case because of how the Court chooses to frame the case. The case, however, communicates quite clearly that the way we currently assess people is perfectly acceptable.

37 Transcript of Senate Judiciary Committee Hearing: Nomination of Hon. Brett M. Kavanaugh to be an Associate Justice of the Supreme Court of the United States (Sept. 27, 2018), https://www.washingtonpost.com/news/national/wp/2018/09/27/kavanaughhearing-transcript/. 
about the characteristics that made them good men and good leaders. According to McGinley and Boyd "The explicit message [from the Senate hearings] was that the nearly-all white plaintiffs were "real men" and "real firefighters" who worked hard and cared for their families." 38 In Justice Kavanaugh's testimony, he repeatedly returned to his athletic prowess in high school as a foundation of his leadership skills and character. As some commentators have pointed out (somewhat flippantly): a teenager who makes it to practice for four years will enjoy the presumption of integrity for the rest of his life. ${ }^{39}$

Like his mentor Kennedy, Kavanaugh recognizes the importance of integrity. The issue here is not whether integrity matters, but rather how we measure it and what we think it consists of. Sports have at least since the industrial revolution been used in schools to build integrity and masculinize men, ${ }^{40}$ but the Kavanaugh episode takes this tradition a step further and mixes up character and competition.

While Ricci and Vargas did not explicitly point to sports for their character bona fides, their refrains of hard work, sacrifice, and "playing by the rules"-a sports metaphor - echo precisely Kavanaugh's list of workout sessions, practices, and captaining his athletic teams. In addition, their testimony displayed their conformance with gender norms (as did Kavanaugh's), ${ }^{41}$ and all three invoke patently masculine definitions of character and leadership. Kavanaugh's testimony exploited the American patriarchal fallacy that success in high school sports is tantamount to having integrity, while the plaintiff firefighters' testimony "lionized a particularly traditional form of heterosexual masculinity" 42 which places "men

38 McGinley, supra note 27, at 584.

39 Justice Kavanaugh mentioned sports nearly fifty times in his testimony. See Lauren Collins, Brett Kavanaugh and the Innocence of White Jocks, The New Yorker, Sept. 28, 2018, www.newyorker.com/news/our-columnists/brett-kavanaugh-and-the-innocenceof-white-jocks-christine-blasey-ford.

40 See Deborah L. Brake, Sport and Masculinity: The Promise and Limits of Title IX, in Masculinities and LaW: A Multidimensional Approach 207 (Frank Rudy Cooper \& Ann C. McGinley eds., 2011) ("In the United States, sports were introduced into schools in response to fears that boys were being feminized by the shift from an agrarian to an industrial labor force, leaving boys in the day-to-day care of their mothers.").

41 From Ricci's testimony: "I studied harder than I ever had before-reading, making flash cards, highlighting, reading again, all my listening to prepared tapes. I went before numerous panels to prepare for the oral assessment. I was a virtual absentee father and husband for months because of it." Sotomayor Confirmation Hearing, supra note 30.

Vargas' testimony: “. . . so I spent three months in daily study preparing for an exam that was unquestionably job-related. My wife, a special-education teacher, took time off from work to see me and our children through this process. I knew we would see little of my sons during these months when I studied every day at a desk in our basement, so I placed photographs of my boys in front of me when I would get tired and went to stop-wanted to stop. I would look at the pictures, realize that their own futures depended on mine, and I would keep going. At one point, I packed up and went to a hotel for days to avoid any distractions, and those pictures came with me. I was shocked when I was not rewarded for this hard work and sacrifice, but I actually was penalized for it." Id.

And Kavanaugh: "I was at the top of my class academically, busted my butt in school. Captain of the varsity basketball team. Got in Yale College.” Kavanaugh Confirmation Hearing, supra note 37.

42 See also McGinley, supra note 27, at 618 ("the promotion process, the lawsuit, the Supreme Court's response, and the Senate Judiciary Committee's hearing, all of which favored the status quo of men living a traditional "manly" lifestyle and doing a traditional "manly" job"). 
at the head of their families, in the traditional role as breadwinner and protector, doings men work." ${ }^{43}$ Both Kavanaugh and the firefighters articulated definitions of character that are patently masculine and, thus, unavailable to those who do not fit into traditional gender norms, nor, really to women at all. ${ }^{44}$

In many ways the similarities between the testimonies are not surprising; with respect to the construction of masculine identity, the firehouse and the frat house at Yale where the respective masculinities were formed are mirror images. The performances of masculinity in both settings have been known to include verbal harassment and physical hazing purportedly designed to create a strong sense of "brotherhood" that is prioritized above all else. The firehouse and college fraternity both value hard work and dedication, and view outsiders, including and especially women, as lacking the dedication, drive, and ability needed to succeed.

Such articulations of straight, white, male "character" in America today prove dangerous because they reify a conception of character that excludes and alienates non-conforming individuals. Therefore, "character," in practice, ends up privileging a particular type of person (e.g., white, straight, men) and, crucially, does so under the neo-liberal pretenses of objectivity and neutrality. Again, as expert witness Janet Helms testified in Ricci (and as Justice Kennedy quoted): "regardless of what kind of written test we give in this country ... we can just about predict how many people will pass who are members of under-represented groups" ${ }^{45}$ - i.e., the white supremacist patriarchy that is America does not provide for anything else. Yet, the marginalized are not told that structural barriers are in place or that subjective decisions are being made against them, but rather that they do not measure up on some objective scale.

Once again, the insidious invisibility of masculinity suffocates those who fail to conform. Beneath the surface of the legal argumentation in Ricci lie internalized determinations about integrity and character that supersede the persuasiveness of any juridical argument a disagreeing Justice could make. Part of the project of masculinity studies has been to expose and objectify masculinity, to no longer allow it to remain hidden behind the cloak of objectivity and neutrality. While it remains hidden, masculinity takes on deific qualities, ubiquitous in the quotidian. This underscores the imperative of masculinity studies exposing, objectifying, and rendering visible the practices of masculinity.

43 Nancy E. Dowd et al, Feminist Legal Theory Meets Masculinities Theory, in Masculinities and the LaW: A Multidimensional Approach 45 (Cooper \& McGinley eds., 2012); McGinley, supra note 27, at 619 ("Instead of engaging in subversive masculine practices, such as violent forms of hypermasculinity, in order to prove their manhood, Ricci and Vargas adhered to the more acceptable traditional masculine norms which describe men's identities as breadwinners and heads of their families. They got married, had children, and worked hard. We find them sympathetic because they followed the script. But this script is not equally available to women and some men.").

44 Collins, supra note 36 ("Try to imagine a Supreme Court nominee returning fifty times to his or her interest in pottery-you can't. ... it's a pretty good deal [conflating competition/sports and character], one that is obviously more available to men than to women, even those who count sports among their passions.").

$45 \quad 557$ U.S. at 571-72. 


\section{A Vicious Cycle: Notions of Hegemonic Masculinity Leading to Perceived Powerlessness That then Result in Harmful Exhibitions of Masculinity.}

A masculinity studies analysis of the Ricci plaintiffs' presentations and the picture of Justice Kavanaugh's teenage years demonstrates how the identity of men is formed equally by male/male relationships as it is by male/female relationships. Sex-based harassment frequently results from a desire to prove the perpetrators' masculinity, rather than to pursue sexual pleasure/gratification, and underlines how society and courts ignore that harassing behaviors and the motives behind them are nearly identical in schools and workplaces. ${ }^{46}$

Prior to the Kavanaugh performance, the last time privileged boys' high school behavior received such public and legal scrutiny was the 2015 case of Owen Labrie. A masculinity studies analysis can help explain how we got from Labrie to Kavanaugh. Labrie, at the time an eighteen-year-old senior at the St. Paul's School, was accused of sexually assaulting a fifteen-year-old as part of the school's "senior salute," a ritual in which male students propositioned female classmates for as much sexual activity as permitted. The New York Times said the case was "at its core, . . . about an intimate encounter . . . between a 15-year-old girl and an 18 -year-old acquaintance, and whether she consented as it escalated." ${ }^{47}$ Ultimately, Labrie was found not guilty of felony sexual assault charges, but was convicted of having sex with a person who was below the age of consent. The legal issues in the case boiled down to a question of consent. Notwithstanding this framing, the case was very much about masculinity, specifically, about how boys "become men" and our culture's role in that process. In the eyes of the law, this case dealt with the legal definition of rape and of consent, and the factual question of whether consent existed.

In feminist theory, male identity is often viewed as coming from a privileged position of power and defined in contrast to females. However, according to masculinity theory, male identity is often formed by feelings of powerlessness and, in contrast, not to females, but to other men. Patriarchy is not based straightforwardly on misogyny; there is a mimetic component to patriarchal violence, like that inflicted by Owen Labrie, that renders the responsibility collective. Unlike feminist theory, that tends to not think of patriarchy outside of a male/female paradigm, masculinity studies recognizes the impact that competition among men has on patriarchy. The desire for hegemonic masculinity does not come from the deep recesses of male souls, as the men's movement would have us believe, but whether we follow Foucaultian theory of desire (desire dependent on power) or a Girardian theory (we imitate the desires of others), the responsibility for the violence of patriarchy is rendered collective.

Male identity is as much about relations with other men as it is about relations with women. Males are perpetually competing with one another over who can come closest to achieving the ideal of hegemonic masculinity. Both the plaintiff

46 See, Ann C. McGinley The Masculinity Motivation, 71 STAN. L. REV. ONLINE 99 (2018).

47 Jess Bidgood, Owen Labrie of St. Paul's School Is Found Not Guilty of Main Rape Charge, N.Y. Times, Aug. 28, 2015, http://www.nytimes.com/2015/08/29/us/st-paulsschool-rape-trial-owen-labrie.html. 
firefighters and Justice Kavanaugh delivered testimony promoting this ideal of hegemonic masculinity. Nevertheless, it is the rare man that meets the hegemonic masculinity standard. ${ }^{48}$ Thus, while men as a group are powerful, individual men do not always or necessarily feel powerful. While the men's movement posits that this powerlessness is a backlash to gains made by women and minorities, masculinity studies suggests that the feeling of powerlessness derives from competition among men to conform to the unattainable hegemonic masculine ideal. ${ }^{49}$ Whether stemming from a backlash or a failure to conform to an unattainable standard, the feeling of powerlessness leads to men's rejection of a core claim of feminism - that men are the most powerful social force. It is for this reason that the equality riddle that feminism is perpetually working to solve must almost necessarily include an analysis of relationships solely between males. ${ }^{50}$

When high school males exhibit toxic masculinity that is sometimes written off as "boys being boys," what they are doing is competing with one another over who best achieves the ideal of hegemonic masculinity that has been communicated to them. ${ }^{51}$ Masculinity scholars have explained how "boys' masculinities include a process of shutting down emotion and taking risks in order to prove manhood." ${ }^{52} \mathrm{In}$ Ricci example and in the Kavanaugh testimony, the ideal of hegemonic masculinity that boys strive for is validated and fêted by the law and the Senate Judiciary Committee. Why is it surprising then, that high school boys feel intense pressure to "prove their manhood"? When viewed through a masculinity studies lens, we can understand that Labrie's participation in the "senior salute" had less to do with his relationship with or opinions about women and girls and more to do with his need to compete with his male peers to meet a standard of masculinity that the law acclaimed in Ricci and Senators glorified in the Kavanaugh hearing. (Was Kavanaugh's "Devil's Triangle" any different from Labrie's senior salute?)

When viewed through a masculinity studies lens, Labrie's participation in the senior salute can be understood not as an explicit brandishing of male power, but as a reaction to a feeling of powerlessness stemming from the perpetual cultural, legal, and political veneration that hegemonic masculinity receives in our society. ${ }^{53}$

Dowd, supra note 7, at 231.

Dowd, supra note 40 , at 44.

so Feminist theory has been more concerned with women and has tended to view the construction of male identity as informed predominantly by males' relationship with females/power over females and the patriarchal dynamic of our society. However, masculinity studies has illustrated how male identity and the existence of patriarchy is equally informed by men's relationship with other men. What this highlights is that the gendering process is relational: "understandings of gender solely through feminist theory or masculinities studies are unidimensional, while gendering is a multidimensional, dynamic, and relational process." Id. at 37.

51 See Dowd, supra note 7, at 233 ("there is also an underlying dynamic in masculinity that pits every man against every man. In addition to being challenged to meet a standard of masculinity that must continuously be performed, masculinity also is a process of comparison, of measuring, that puts each man against all others.").

52 Dowd, supra note 40 , at 31 .

53 The feeling of powerlessness that many men feel is real even if it is not always entirely accurate: "we have long recognized that irrationality sustains much of the unconscious as well as conscious thinking about inequalities of gender, as well as those of race, class, and sexual orientation. What may be most important is to understand that this conviction is real and stands in the way of changing consciousness of men about men, 
Society continuing to place a particular form of hegemonic masculinity on a pedestal encourages men to engage in a constant struggle with other men to prove their masculinity and inevitably results in instances of masculinity gone astraylike Labrie and Kavanaugh.

\section{Perspective Is Everything: Endorsing a Particular Kind of Masculinity by Pretending It Doesn't Exist}

While the law holds itself out a neutral arbiter, the Kavanaugh and Ricci examples reveal the ever-present straight, white, male lens through which the law views disputes. The image of the blindfolded, robed woman holding a set of scales might represent, instead, the law's failure to see that which is not male. By continually affirming the validity of a particular male perspective, the non-juridical power of the law propagates a particular form of masculinity. The law repeatedly communicates the reasonableness and fairness of this perspective, without actually addressing it, until ideas like "men should be breadwinners" and "character and competence are interchangeable" become internalized.

Arguably the most important role played by judicial opinions, particularly appellate opinions, is to educate prospective litigants, lawyers, and lower court judges. ${ }^{54}$ In Ricci, for example, the law is signaling to employers what they can and cannot do in order to render their hiring practices non-discriminatory and, importantly, signaling to employees, potential employees, and the larger community whether or not certain hiring practices are acceptable. This educational component of judicial decisions both provides concrete direction that applies to very specific sets of facts and creates structures and systems that suggest legally correct ways of approaching and seeing the world. The educational role of the law consists of disseminating a specific perspective to receptive audiences. There is nothing "natural" or "correct" about seeing the world in the way presented by the law; it is just one way among many to make sense of the world.

The law, with respect to its educational role, is more focused on the reasons why the judgement is made than on the decision itself..$^{55}$ The reasons provide guidance and perspective. The reasons are what communicates to the audience the way they should view the world and the principles and values which should form their sensibilities. What the law is ultimately doing here is creating norms and standards that guide its citizenry; it is exercising its non-juridical power. Indeed, this educational role is a major reason that thinking about the power of the law as being primarily juridical misses its biggest impact.

Two common elements in the Ricci and Kavanaugh examples help us understand the law's power to act in this non-juridical capacity. Traditionally, hegemonic masculinity contained an element of stoicism; however, that stoicism was not present in the testimony of Ricci, Vargas, or Kavanaugh. All three presented themselves as victims. This willingness to articulate one's victimhood and explain

and of women about men so that movement toward equality is possible." Dowd, supra note 7 , at 233 .

54 See generally Mitu Gulati et al., The New Old Legal Realism, 105 Nw. U. L. Rev. 689. (2011).

55 Consider the importance of Roe $v$ Wade being decided on privacy grounds rather than equal protection grounds. 
to crowds of people how wronged one has been is a relatively new component of masculinity. The impetus for this willingness to play the victim is readily traced to the men's movement and its belief in and highlighting of the disempowering effects of the civil rights movement on straight white men. ${ }^{56}$

The victimized white male became the prevailing perspective in each confirmation hearing and in Justice Kennedy's decision. ${ }^{57}$ In both hearings, the other side was heard from, but the alternative perspective was discarded.$^{58}$ The three male witnesses were repeatedly congratulated for their hard work, courage, and strength to stand up to the unfairness to which they were exposed. During Ricci's confirmation hearing testimony, Senator Lindsey Graham emphasized how Ricci had been wronged: "I appreciate how difficult this must have been for you, to bust your ass and to study so hard and to have it all stripped at the end." ${ }^{, 59}$ Interestingly, it was Senator Graham whose diatribe at the Kavanaugh hearing switched the tenor of the remainder of Committee Republicans' questioning and even the delivery of Kavanaugh's testimony itself from calm and measured to an outrightly hostile and aggressive presentation about how Kavanaugh had been wronged. When given his five minutes, Senator Graham's face reddened and pointing his finger he boomed: "This is the most unethical sham since I've been in politics . . I cannot imagine what you and your family have gone through . . . if you are looking for a fair process, you came to the wrong town at the wrong time my friend." ${ }^{60}$ Vargas and Ricci were lauded by the Committee Republicans because they represented right against wrong in the lawsuit. ${ }^{61}$ The prevailing narrative in both hearings was that these men had been wronged, they had been treated unfairly, they were victims.

56 Indeed, the Senate Judiciary Committee Republicans embraced the narrative of victimhood in order "for white, upper-middle class male senators to confirm to the people back home that they believed in hard work, that they understood the plight of the white working man, and that they did not intend to let him down." McGinley, supra note 27 , at 584.

57 While Justice Kennedy never mentions perspectives of those perhaps harmed by the decision, Justice Ginsburg attempts twice to include the perspective of the aggrieved white firefighters in her dissent: "The white firefighters who scored high on New Haven's promotional exams understandably attract this Court's sympathy. But they had no vested right to promotion;" "It is indeed regrettable that the City's noncertification decision would have required all candidates to go through another selection process." 557 U.S. at $608,644$.

58 During the Sotomayor confirmation hearings, two witnesses testified on behalf of thenJudge Sotomayor's Ricci decision. But even those who supported her were less than enthusiastic about the decision: "Judge Sotomayor has participated in thousands of cases and authored hundreds of opinions, but much of the debate about her nomination has concentrated on the difficult case of Ricci v. DeStefano. Whatever one may feel about the facts in this case, we all agree that the Supreme Court in its Ricci decision set a new standard for interpreting Title VII of the 64 Civil Rights Act. Using this one decision to negate Judge Sotomayor's seventeen years on the bench does a disservice to her record and to this country." Sotomayor Confirmation Hearing, supra note 30. (Hardly a glowing review.) And while the Committee listened to Dr. Christine Blasey Ford testify about her vivid memory of being sexually assaulted by Justice Kavanaugh, the Republicans on the Committee either did not believe her or did not care about what she had to say.

59 Sotomayor Confirmation Hearing, supra note 30.

60 Kavanaugh Confirmation Hearing, supra note 37.

61 See Dowd, supra note 40, at 43. 
Of course, this white, male victim perspective was not the only one the Court and the Senate Judiciary Committee could have embraced. What about the Black, Latino, and female firefighters who had not succeeded in the exam? What about the Black applicants who did much better in the oral part of the exam? ${ }^{62}$ What about the role of the law as educator ... what message was being communicated to both the white firefighters and to the female, Black, and Latino firefighters? What message was being communicated about how character is measured? What is being communicated to young girls about their opportunities? The perspective embraced is that of the aggrieved, innocent, white man. The voices of those unable to become firefighters because of the structural and systemic disadvantages they encounter are not heard.

When decisions are rendered that blatantly mischaracterize an existing law or when society must deal with cases of explicit bigotry or sexism, locating and remedying the problem is a more straightforward exercise then when one is dealing with an issue of perspective. Masculinity exerts its power more subtly in this context. Perhaps its most ubiquitous characteristic is its invisibility, which manifests here as an ability to shape the perspective through which issues are viewed. Hidden under the liberal cloaks of neutrality, merit, fairness, and colorblindness, one perspective is adopted, and others are marginalized. The perspectives adopted and endorsed by the law in the Ricci and Kavanaugh examples demonstrate the importance of question framing as opposed to simply arguing the merits. When we ask whether the Ricci firefighters merited promotions we have chosen the wrong framing because the validity of the tools that were used to assess merit is itself in question. Similarly, if we ask the question of whether or not Brett Kavanaugh sexually assaulted his teenage peer Christine Blasey, larger systemic issues like how our society defines sexual assault, how it is proved, how victims who speak out are treated, and whether a past assault should disqualify a person from elevation to a seat on the highest court are ignored and voices other than that of the accused are marginalized.

\section{SuCCESSFUl InCORPoration of FeMinist TheOry Insights}

As explained above, like feminist theory, masculinity studies is an emancipatory project. Initially, discrimination and patriarchy were conceptualized as problems of equal treatment - problems tailor-made for the law to tackle. But once patriarchy emerged as structural and equality not simply as something formal, solutions proved more elusive. The depressing conclusion that patriarchy was built into the discursive arrangements of society complicated the goal of emancipation. However, because the law has historically served as a relatively receptive place for rightsbased arguments and because success can be measured in more tangible ways in the legal arena (after all, one can win a case), the law continues to be viewed by many an attractive avenue for addressing the problems of patriarchy. Notwithstanding ingrained problems of perspective revealed in Ricci that permeate the law, for advocates it remains a space to fight patriarchy, rather than one that perpetuates it.

62 "No one asked why the black men who took the test scored significantly better on the oral part of the test than on the written portion. No one questioned whether the test results would necessarily locate the persons who would be best for the jobs. All equated test results with merit and with hard work." McGinley, supra note 27, at 618. 
Rights-based arguments were, in many ways, conceptualized to appeal to an individuated, neoliberal, legal system based on the reasoned elaboration of principles and policies. In addition, feminist equality/difference arguments are something that the law is inherently receptive to - particularly in areas of employment lawbecause the masculine subject position remains the de facto norm against which the alternative position will either be found equal to (with the male remaining the norm) or different from (confirming the inimitableness of masculinity). Equality, or lack thereof, for example, is not the reason that women are paid less for the same work as men; the reason is, rather, that society does not value the work that women do the same way it values the work that men do. As the expert witness in Ricci, Janet Helms, pointed out, the table has already been set by the time the guests show up to dinner; racist and patriarchal relations inform the very production of subjects in the first place. Therefore, legal claims of "equality" will never actually threaten the balance of power. Until the production of subjectivity can occur within gender relations that are not patriarchal, we (like Helms) will not need to look at the tests to know what the results will be.

Lip service has been paid to the dependence of masculinity studies on feminist theory, yet not all of the significant insights from feminist theory have received their due consideration. Masculinity studies has succeeded in incorporating certain insights (about essentialism, intersectionality, substantial equality, sex roles, and hegemonic masculinity), ${ }^{63}$ while it has been less successful at incorporating others (e.g., issues of power, the "search for origins," the authority of experience, and the political nature of sexual difference/categories).

\section{A. ESSENTIALISM}

Masculinity studies encountered essentialism within the context of men as a social category existing as oppressor and as homogenous - a category, it was argued, that failed to account for the diversity and complexity of men's lives. This reductionist approach brushed over critical differences among men, like race, class and sexuality, which radically altered the experience of being a man in the world. Masculinity studies was forced to address a patriarchal system in which it was assumed that all men benefited equally from male supremacy. Indeed, the tendency to characterize men as a homogenous and oppressive group risks ignoring the dangers of hegemonic masculinity, which, as we have seen in the Labrie example, leads to feelings of powerlessness and inadequacy that affirm our patriarchy. A further risk in essentializing male identity is that the complicated process of identity creation for men is not taken seriously and relationships between males-recall Ricci's firehouse and Kavanaugh's fraternity house - are seen as less intrinsic to patriarchy than relationships between men and women.

Within feminist theory, anti-essentialists have criticized the biologistic basis of certain strands of feminism that have a one-dimensional view of women, which suggested that victimhood was an almost immutable condition, counterpoised against a similarly reductivist view of men as oppressors. ${ }^{64}$ The construction of

63 Essentialism and intersectionality are discussed below; the other enumerated insights are discussed in an expanded version of this paper.

${ }^{64}$ Margaret Thornton, Neoliberal Melancholia: The Case of Feminist Legal Scholarship, Australian Feminist L.J. 20, 10 (2004). 
men in this manner created an all-powerful category, with every member part of a seemingly omnipotent global cabal. Indeed, characterizing the male experience in this way ultimately hindered attempts at empowering women and was seen as equally androcentric as the theories it attempted to supersede. Nonetheless, work continued to be done illustrating how, while differences exist among men and certain men benefit from patriarchy more than others, all men benefit from patriarchy in some sense. This "benefit" has been called the patriarchal dividend: the advantage men in general gain from the subordination of women and from being complicit in the hegemonic project without the tensions or risks of being on the front line of patriarchy. ${ }^{65}$ (Many self-identified progressive men do not do laundry.)

Written into arguments about essentialism are perhaps the most intuitive replies when one challenges the biological foundations of sex categories: what about chromosomes, what about testosterone, what about estrogen? ${ }^{66}$ The essence to sex categories, the argument posits, is that males have one $\mathrm{x}$ chromosome and one y chromosome and females have two x chromosomes, and that males are full of testosterone and that females are full of estrogen. ${ }^{67}$ However, these arguments lack a biological basis. According to Dr. Anne Fausto Sterling: ${ }^{68}$

What matters, then, is not the presence or absence of a particular gene but the balance of power among gene networks acting together or in a particular sequence. This undermines the possibility of using a simple genetic test to determine "true" sex." And of the Trump administration's attempt to legally define sex as "a person's status as male or female based on immutable biological traits identifiable by or before birth" stated: "It flies in the face of scientific consensus about sex and gender, and it imperils the freedom of people to live their lives in a way that fits their sex and gender as these develop throughout each individual life cycle. ${ }^{69}$

5 Connell, Masculinities, supra note 1, at 79.

66 See Lynn Liben, Probability Values and Human Values in Evaluating Single Sex Education, in SEx Roles 410 ("Males and females are assumed to have different 'essences' that, although largely invisible, are reflected in many predispositions and behaviors. These essences are given - at the individual level-by a range of genetic and hormonal processes and - at the species level-by evolution. They are viewed as part of the natural order, likely to be presumed to operate across contexts and across the lifespan, and often presumed to be immutable (at least in the absence of herculean and unnatural efforts to change them.").

67 The question of addressing opposition to the consensus in the scientific community regarding sexual difference is more relevant than ever considering the Trump administration's attempts to "define transgender out of existence." See Erica L. Green, 'Transgender' Could Be Defined Out of Existence Under Trump, N.Y. Times, Oct. 21, 2018, https://www.nytimes.com/2018/10/21/us/politics/transgender-trumpadministration-sex-definition.html.

68 See generally Anne Fausto Sterling, Sexing the Body: Gender Politics and the Construction of Sexuality (2000); Claire Ainsworth, Sex Redefined, Nature (Feb. 15, 2015); Cordelia Fine, Testosterone Rex: Myths of Sex, Science, and Society (2017).

69 Anne Fausto Sterling, Why Sex Is Not Binary, N.Y. Times, Oct. 25, 2018, https://www. nytimes.com/2018/10/25/opinion/sex-biology-binary.html. 
The consensus in contemporary sex determination science now recognizes that genetic sex is not located in a stark binary but is scattered about the genome. Furthermore, the correlation between chromosomes and hormones with the brain and behavior is even more fallacious and harmful: "the effect of the genetic and hormonal facets of sex on the brain and behavior must not inflexibly inscribe or 'hardwire' particular behavior profiles or predispositions into the brain." course, the fact that sexual difference is constructed, is not "natural" or determined by chromosomes, does not make it any less real. ${ }^{71}$

Essentialism also appears under the guise of values and cultural attributes that are encoded as masculine. Autonomy, reason, individualism, aggressiveness, and self-sufficiency serve as the basic tenets of liberal legalism and are generally thought of within western political culture as quintessentially masculine. Thus, while essentialism on the one hand reduces the complexity of men's experience it also genders otherwise gender-neutral cultural characteristics. It is this dynamic that leads to the internalization of a particular perspective by Justice Kennedy in Ricci, which ends up privileging white men. Both law and masculinity are constituted in discourse and the overlap intertwines the two: the law, like masculinity, is constructed as rational and natural. It is this association that renders cases like Ricci arguably just as important as cases that deal explicitly with rape/sexual assault law in the struggle against patriarchy. Dismantling patriarchy is as dependent on defying heterosexism and reshaping ideas about fatherhood, or challenging implicit connections between character, integrity, and masculinity like those seen in Ricci, as it is on the specifics of Family Law. The ostensibly gender-blind discourse of law in Ricci in fact replicates the patriarchal order in the other areas of our social lives. It is this challenge to naturalistic assumptions about masculinity which recalibrates the debate as being more about politics and less about revealing hidden gendered assumptions that permeate the social world. In other words, when the naturalistic assumptions about masculinity are exposed, the political and ideological components can be challenged. For instance, the task becomes not locating where in the social world reason is being privileged over emotion, but rather disentangling the forces that bind masculinity to reason in the first place and to exposing their political nature. Consequentially, connections that appear commonsensical when the naturalistic assumptions are applied are exposed as teleological when those assumptions are removed. For instance, Smart deconstructs the connection among rationality, men, and lawyering: "So law is not rational because men are rational, but law is constituted as rational as are men, and men as the subjects of the discourse of masculinity come to experience themselves as rational — hence suited to a career in law." 72

\section{B. INTERSECTIONALITY}

Related to the idea of essentializing the experience of being male is the concept of how to account for differences among men like race, class, and sexuality, and

\footnotetext{
70 Cordelia Fine, Testosterone Rex: Myths of Sex, Science, and Society 87 (2017).

71 Fausto Sterling, supra note 65, at 27, n.135 ("Just because something is constructed does not mean that it is not real." (citing Fujimura); "The bodies are perfectly 'real.' Nothing about corporealization is tropic and historically specific at every layer of its tissues." (citing Haraway).").

72 Carol Smart, Feminism and the Power of LaW 87 (1989).
} 
how to avoid simply writing in those differences on top of the heterosexual white male experience. This problem was addressed in feminist theory under the rubric of intersectionality - a concept pioneered in the work of Kimberlé Crenshaw. ${ }^{73}$ Within the context of masculinity studies, the question becomes how these cultural characteristics impact the way particular individuals experience and perform masculinity. Much of the work in this tradition has focused on cultural representations of masculinity and how the specific histories and identities of individuals engage with those cultural representations. ${ }^{74}$ In this sense, each individual has a unique encounter with hegemonic masculinity — one that is neither necessarily positive nor negative and which, therefore, can help identify why certain subjects have different reactions to masculinity.

Ricci serves as a paradigmatic example of Black and Latino male firefighters not being able to access the privileges available to the white male firefighters, who nonetheless experience the whole process very differently than women firefighters did. The Ricci majority ${ }^{75}$ opinion does not once mention the experience of women firefighters with the test. The uniqueness of the subject position of the Black firefighter is one where they experience firsthand the privilege of their gender and the discrimination of their race. This particular intersectionality is one that has not been thoroughly interrogated in feminist theory, since women are do not feel the privilege of the gender hierarchy, but should still be considered.

Masculinity studies has recognized that an intersectional analysis is fundamental in understanding identity creation. The intersectional analysis takes on different dynamics when applied to masculinity rather than femininity. Whereas, in feminist theory, being a woman (not an already privileged cultural category) intersected with race, class, and sexual orientation, in the case of men, an already privileged identity intersects with these same components. Thus, while Black women are in a sense doubly burdened, subject in some ways to the dominating practices of both a sexual and a racial hierarchy, ${ }^{76}$ a Black man, in a sense, dominates the sexual hierarchy and is marginalized racially. However, one of the crucial insights from feminist theory about an intersectional analysis is that Black women's suppression cannot simply be reduced to white women's suppression plus Black men's suppression equals Black women's suppression. This reductionist equation fails to understand the unique position of Black women within the hierarchies of power. The position of Black women in dominant American social relations is in many senses unassimilable into the discursive paradigms of gender and race domination, and therefore many of the dominant discourses of resistance available to white women and Black men are unavailable to Black women. ${ }^{77}$ Furthermore, the structure of the legal system

73 Kimberlé Crenshaw, Demarginalizing the Intersection of Race and Sex: A Black Feminist Critique of Antidiscrimination Doctrine, Feminist Theory and Antiracist Politics, U. Chi. Legal Forum 1 (1989).

74 See Stuart Hall, Representation: Cultural Representations and Signifying Practices (1997).

75 In her dissent Justice Ginsburg mentions Johnson v. Transportation Agency, Santa Clara Cty., 480 U. S. 616, which examines the contours of disparate treatment legislation from a male/female context.

76 Kimberlé Crenshaw, Whose Story Is It, Anyway? Feminist and Antiracist Appropriations of Anita Hill, in Race-Ing Justice, En-Gendering Power 404 (Toni Morrison ed., 1992).

77 Id. 
forces Black women, if they want legal recognition, to fit their experiences into known, understandable, and palatable pre-existing narratives. ${ }^{78}$ The manner in which racism and sexism are thought about in dominant American social relations often precludes those stories which do not fit nicely into the narratives of white women and Black men. When racism and/or sexism take more nuanced forms than the prevalent modes understood by mainstream society, the methods of resistance at the disposal of the subjugated are severely diminished. An intersectional analysis was vital when examining, for example, the inability of Anita Hill to effectively communicate the reality of her experience at the Senate confirmation hearing of Clarence Thomas. Because she was situated within two fundamental hierarchies of social power, the central disadvantage that Hill faced was the lack of available and widely comprehended narratives to relate her story. ${ }^{79}$

If thinking about Black women's oppression simply as being "doubly burdened" is inadequate and inaccurate, then similarly thinking about Black men's position using the equation: sexual privilege minus racial discrimination equals Black men's experience is necessarily reductionist and fails to capture any semblance of the reality of Black men's experience. The question becomes one of understanding how an intersectional analysis applies to men who are subjugated in some other area of social relations - notably race, sexuality, or class. The denial of privileges offered to white men often results in masculinity manifesting itself in different ways (ways which often support male privilege even when the particular men in question do not benefit from it themselves). A fundamental tension lies between thinking about all men benefiting from a patriarchal dividend and simultaneously recognizing that masculinities that do not fit within the dominant paradigms cannot readily access that privilege. An intersectional analysis reveals the shortcomings of a gender analysis, a class analysis, a racial analysis, or a sexuality analysis, in and of themselves. An effective analysis must examine the workings of power more overarchingly and engage with how each of the social hierarchies work together to marginalize certain groups of people.

As in the early days of feminist theory - where gender was used to distinguish between what was seen as "natural" (sexual difference) and what was seen as a social construct (gender)-masculinity studies spends much energy struggling against naturalistic and essentialist conceptions of masculinity. ${ }^{80}$ In contrast to feminism, though, masculinity's relationship to equality is not a conventionally aspirational one. Men's relationship with equality is not complicated because of a lack of power, like women, but rather because of the enormous power they hold.

78 Id. ("The particularities of black female subordination are suppressed as the terms of racial and gender discrimination law require that we mold our experience into that of either white women or black men in order to be legally recognized.”).

79 Id.

80 See Dowd, supra note 7, at 201-04 ("Feminist Theory has examined men, patriarchy, and masculine characteristics predominantly as a source of power, domination, inequality, and subordination...In much feminist analysis, men as a group largely have been undifferentiated."). And masculinity studies, unlike feminist theory, has not engaged the distinction between sex and gender. Collier, supra note 1, at 466 ("This critique of the division between (biological) sex and (socially constructed) gender, present within, if still marginal to, much contemporary work on masculinities, can be located within the context of broader attempts within feminist sociological theory and socio-legal work to transcend binary oppositions that have informed understandings of gender and law.”). 
Equality, for masculinity studies, as opposed to feminist theory, is not about equality of opportunity, power, or freedom, but rather about coping with, recognizing, and relinquishing privilege. This adds a dynamic to masculinity studies not necessarily present in feminist theory. Part and parcel with reconciling men's relationship with privilege is distinguishing between individual men and men as a group. Considering that the de facto male subject position is one of privilege, masculinity studies continues to sometimes contribute to a culture of victimhood within nonhegemonic masculinities, and thus fails to recognize the "patriarchal dividend." 1

Generally, within masculinity studies there ought to be a self-awareness that while essentializing and naturalizing masculinity is harmful to both men and women, we nonetheless continue to live in a patriarchal system with men holding power over women. Indeed, hegemonic masculinity need not be enacted to have consequences. The power is always available to men whether they want to use it or not: "this is the mechanism through which every male enacting an identity as a man, whether he strives to enact hegemonic masculinity or not, is granted male privilege - cultural benefits and unearned advantages conferred by virtue of membership in the social category men." ${ }^{22}$ However, importantly, this process reminds us that male privilege is not absolute or universal, and gender privilege, as well as subordination, is differentiated along race, class, and sexual orientation lines.

\section{OPPORTUNITIES FOR INCORPORATING FEMINIST THEORY INSIGHTS}

Despite the success of masculinity studies in incorporating insights about essentialism and intersectionality gleaned from feminist theory, there are four other insights that masculinity studies has failed to take as seriously as it could. In part, the history of masculinity studies and the presupposition of masculinity as an object of study are responsible for such failure. The framing of masculinity occurs within a white, heteronormative conception of gender that essentializes male/female difference and tends to ignore differences within gender categories. "[T]he concept of masculinity is said to rest logically on a dichotomization of sex (biological) versus gender (cultural) and thus marginalizes or naturalizes the body." ${ }^{83}$ A slight variation to this point is that the importance of focusing on masculinity as its object of study has led masculinity studies to have a sharp disinterest in the female subject; in masculinity studies, "separatism is a hallmark, then of much of masculinities scholarship." ${ }^{84}$

81 Nancy E. Dowd, The Man Question: Male Subordination and Privilege 61 (2010) (The patriarchal dividend are the benefits "that all men have from the overall dominance of men in the gender order" and "from the reinforcement of male dominance."). Nevertheless, masculinity studies recognizes that, often, "men, although powerful, feel powerless." Dowd, supra 40, at 28.

82 Matthew B. Ezzell, Healthy for Whom?-Males, Men, and Masculinity: A Reflection on the Doing (and Study) of Dominance, in ExPloring Masculinities: IDENTITY, Inequality, Continuity, AND Change 190 (Pascoe \& Bridges eds., 2016).

83 R.W. Connell \& James M. Messerschmidt, Hegemonic Masculinity: Rethinking the Concept, 19 Gender \& SOC'y 6, 836 (2005).

84 Dowd, supra note 7, at 33. 
This theoretical foundation has led to segregative thinking when it comes to addressing practical concerns. ${ }^{85}$ The assumption of gender difference both creates a disinterest in the other gender among those looking for solutions to problems characterized as only impacting a particular gender, and often contains within it a built-in remedy. ${ }^{86}$ The tendency is to make gender analysis a zero sum game: either you analyze the impact on men or the impact on women, or you analyze something other than gender. Thus, the incorporation of issues and insights that are not specific to masculinity has had trouble gaining traction in masculinity studies. Masculinity studies should show more of an appetite for thinking beyond the confines of masculinity.

\section{A. POWER ANALYSIS}

The first concern centers on power. In many respects, though by no means all, the impetus behind masculinity studies is the existence of patriarchy, and, thus, an understanding of the oppressive power of male supremacy is central to masculinity studies. Patriarchy generally conceptualizes power as repressive. Masculinities scholars tend to evaluate the ways that conceptions of masculinity are used to produce power. Partly because a so-called "power analysis" remains the centerpiece of feminist advocacy - the struggle to equalize power between the sexes - masculinity studies has been focused on the issue of power within society and within masculinity. ${ }^{87}$

Hegemonic masculinity is founded on the idea that it exerts a normative power on men to conform to its tenets - as discussed above with respect to the Labrie case. Thus, power manifests in a juridical manner in two distinct ways - both as supremacy over females and over men who do not conform to conventional gender identities. ${ }^{88}$ Male power though, in both of these dynamics, exerts its might in an essentialist manner. In other words, power is more or less characterized as univocal and oppressive; it is one dimensional and focused on men as a group having power over women as a group and over men who "do" masculinity differently.

Masculinity studies scholar Jeff Hearn has posited that "while power functions, flows and re-forms in multiple ways, it is difficult to avoid the fact

$85 \quad I d$. at 39 ("segregative thinking - thinking about legal problems as affecting a single sex and requiring a sex-specific remedy"); see also David S. Cohen, Sex Segregation, Masculinities, and Gender-Variant Individuals, in MASCULINITIES AND THE LAW 168 ("Understanding sex segregation should be a vital part of the study of law and masculinity. In fact . . . current-day sex segregation is one of the central ways that law and society define and construct who is a man and what it means to be a man.").

86 Dowd, supra note 7, at 40 (discussing gender-specific education and how researchers looking to solve the "boy crisis" in education, since they have already divided their constituency by gender, end with a sex-segregative remedy).

87 See Chris Weedon, Feminist Practice and Postructuralist Theory 1 (1987) ("Feminism is a politics. It is a politics directed at changing existing power relations between women and men in society. These power relations structure all areas of life, the family, education and welfare, the worlds of work and politics, culture and leisure... as feminists we take as our starting point the patriarchal structure of society.").

88 See Cohen, supra note 78, at 168 (discussing hegemonic masculinity and the hegemony of men). See also Jeff Hearn, From Hegemonic Masculinity to the Hegemony of Men, 5 (1) Fem. Theory 49 (April 2004). 
that in most societies, and certainly those of western, 'advanced' capitalism, men are structurally and interpersonally dominant in most spheres of life." ${ }^{89}$ Thus, "looking at gender and power is an important part of the anti-essentialist project, as essentialist notions of gender reinforce power structures. ${ }^{90}$ Challenging dominant notions of masculinity has an impact on disrupting the hegemony of men. To Hearn, the project should focus on the hegemony of men, which he defines as "that which sets the agenda for different ways of being men"91 rather than on the identification of hegemonic masculinity, and, in this way, have the focus be more individualized.

The analysis of power within masculinity studies has employed various frameworks. Two of the most prevalent are: a capacity to dominate others, and ideological conditioning. ${ }^{22}$ The second view directs one to a more structural level. It strays slightly from a juridical understanding of power, yet by emphasizing the ideological components, it nonetheless highlights its agentic components. The analyses of power in masculinity studies, therefore, continually fail to seriously engage with the production of masculinities from a perspective that sees power as productive and, crucially, discursive. Further, if power is recognized as productive, then its ideological components ought not to be the focus of the analysis, as this analysis suggests a misunderstanding of the role played by individual subjects. Individual subjects do not simply own an amount of power which they deploy as they see fit. Power flows between individuals and is thus not wholly subject to the whims of specific individuals. Power, in that sense, is both relational, and dependent on those who have some and those who have none. Hearn has suggested that masculinity studies should ask "which men and which men's practices . . . are most powerful in setting those agendas of those systems of differentiations, ${ }^{93}$ here we see, once again, an example of the intentionality only present in a juridical understanding of power being considered.

Masculinity studies gives lip service to the idea that power flows, but continues to paint a picture of it as something that functions juridically. There is the sense of something ideological going on; dismantling patriarchy is conceived of as a political project, yet political in the wrong sense. The fight against patriarchy has emerged as a contest to root out sinister masters of the universe who pull society's levers. The focus on hegemony is "about the winning and holding of power and the formation (and destruction) of social groups in that process ... hegemony involves persuasion of the greater part of the population, particularly through the media, and the organization of social institutions in ways that appear 'natural', 'ordinary', 'normal'." 94 This operation foregrounds the individual subject and position him in a dominating position that again views power as hierarchical rather than circulatory.

Hearn, for instance, while at numerous times suggesting that he thinks about power as something that flows and should not be conceptualized in a unitary sense, distinguishes between men who both are formed in the hegemonic gender order and form the hegemonic gender order, and women who are solely formed in it. This

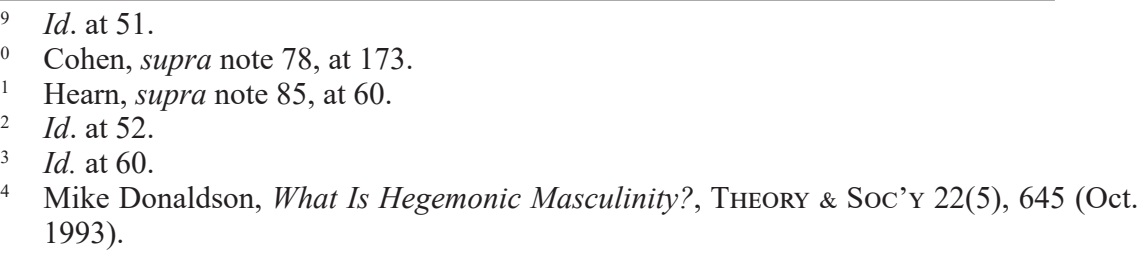


understanding of power is one directional, with women being the passive recipients of the force of power deployed by men. While it is easy to say that "power flows," it is much more difficult to theorize ways of making sense of masculinity while accepting that premise. This is true both because a juridical understanding of power has been internalized by most in our society; it has become common sense. As Butler reminds us, "power is not stable or static, but is remade at various junctures within everyday life; it constitutes our tenuous sense of common sense, and is ensconced as the prevailing episteme of a culture." ${ }^{95}$ It is more difficult to find solutions when thinking about power in that sense. It is easier to address and counteract patriarchy when it is conceptualized as something ideological, complete with intentionality and agentic subjects directing it.

The concept of hegemonic masculinity, for instance, derived from masculinity studies, provides an analysis of power that is exceedingly helpful to understand the process of male identity creation. For instance, with respect to the Labrie case, this concept renders it easier to comprehend the powerlessness felt by many young men and that the perpetuation of patriarchy is just as much about competition among men as it is about misogyny. Masculinity studies, however, tends to pinpoint the idea, in the sense that it is very good at locating examples of where hegemonic masculinity appears, yet it is less successful at deconstructing the idea. It tends to characterize hegemonic masculinity as stable, controlled, and somewhat selfserving; it is interested in understanding how power dominates, yet understanding the complexities and relationality of power makes dealing with hegemonic masculinity more difficult than locating it.

\section{B. SEARCHING FOR ORIGINS}

A second problem with the current direction of masculinity studies is that, because it remains tied to an emancipatory ethos, it is focused on a misguided search for origins. The project remains guided by a search for a freedom beyond patriarchy and, in this way, is always intertwined with liberalism. Masculinity studies is tied to the project of locating masculinity, which involves asking whether masculinity existed prior to its production through social structures, and, if it did, then somehow rendering "the problem" less to do with the action of actual men. The search for origins drowns out the experiences of particular individuals, marginalizes male practices, and "involves an evacuation of questions of responsibility and agency." 96 Thus, on the one hand, masculinity studies remains tied to an idea of power as ideological conditioning, which grants individual subjects too much agency, and, on the other, it remains committed to a "search for origins," which takes agency away from individual subjects. Masculinity studies perpetually struggles with this "agency" balance.

In Ricci, the search for origins problem manifests quite clearly, particularly in the arguments suggested by the expert witness Janet Helms. Recall that Helms did not need to look at tests to claim that she knew how minority candidates would perform in it. As she recognized, equality is impossible in a world where patriarchal relations inform the production of the subjects. It is not possible to reach a pre-

95 Judith Butler et al., Contingency, Hegemony, Universality: Contemporary DiAlogues ON THE LeFT 14 (2000).

96 Collier, supra note 2, at 468. 
patriarchy place. Indeed, even the tools of legal method which had been presumed to be neutral have now been exposed, and ideas like equality itself, are problematic because one is always equal to something. A masculinity studies analysis of Ricci, therefore, allows one to see that a case that apparently has nothing to do with gender is actually infused with patriarchal ideas, yet it continues to wrongly suggest failed ideas for moving beyond them.

The problems tied to the "search for origins" are one of the reasons that the usefulness of masculinity as an analytical category has been questioned by theorists who argue for a shift of attention to men's actual practices. But that shift remains emancipatory and problematically suggests that the problem of patriarchy is solvable by changing the actions of men. The trend in masculinity studies has been to narrow the scope, to move away from grand theories, to focus on the local, where change can be seen and felt. While this does provide some sense of tangible change, it ultimately suggests that patriarchy is solvable by ridding the world of the "bad" acts of men and that the existence of patriarchy itself is due to these particular "bad" acts of men. This has the effect of ultimately disempowering those subjects who do not identify as men because they are characterized as not being a part of or having a role in what has created the social world.

Further, part of the reason that masculinity was initially thought of as being a ripe area of study, in contrast to simply thinking about the actions of men which perpetuate male supremacy, is that there were structural, political, and theoretical impasses identified in feminist theory that were not "solvable" simply by identifying these patriarchy perpetuating acts. Focusing on the hegemony of men, rather than on masculinity, fails to recognize that the category of men is equally problematic, and constructed, as the category of masculinity. Trying to move beyond masculinity to men suggests the knowability of some sort of original position, some sort of prediscursive, pre-gendered position, from which actions were taken which resulted in patriarchy, and that emancipation is possible by re-tracing and reversing those actions.

The insight from feminist theory to be worked from is not identifying the actions of subjects who identify as men which contribute to the domination and subordination of others, but rather to be critical of the existence of the categories in the first place. Each of these tasks appears political, yet the more radical position and the position that offers the least feel-good results is that of critiquing sexual difference/categories as a whole. This is not to suggest, necessarily, that the project should be to dismantle sexual categories (sexual categories are perhaps re-signifiable to serve ends that do not contribute to male supremacy), ${ }^{97}$ but that engaging in the process of examining particular acts, rather than holding men accountable, is actually disempowering and perpetuates the system as a whole. In short, the question becomes is it possible to preserve gender without preserving domination ? $^{98}$

97 Although the idea of any hegemonic masculinity serving progressive ends seems far-fetched. As one commentator has asked: "What exactly does one do nowadays to inhabit a malepositive gendered identity that feels - and is - worthy of respect (by oneself and others)?" John Stoltenberg, Why Talking about Healthy Masculinity Is Like Talking about Healthy Cancer, Feminist CurRent (Aug. 9, 2013). Stoltenberg argues that attempting to attain a "healthy" masculinity just "reinvigorates the disease." Id. Examining how social agents "do" masculinity through a normative lens perpetuates the existence of gendered hierarchies.

98 Michael Schwalbe, Manhood Acts: Gender and the Practices of Domination 170 (2014). 
Again, this is not to suggest that in a practical sense these actions should be condoned or ignored, but that the job of masculinity studies should be about addressing the categories themselves, rather than just focusing on the actions, which only serve to reify those categories. When the point of masculinity studies is thought of as being emancipatory - that masculinity studies has a goal and that the goal is equality or freedom or the dismantling of patriarchy - then masculinity studies is expressing its problem with origins. The concern of disembodying masculinity from men, of divorcing an analysis of masculinity from the "real" impact of the actions of men, suggests that masculinity studies should focus on equalizing power between categories, rather than on the validity of the categories themselves. Collier has cautioned against remaining tied to masculinity and has suggested re-theorizing men identities "in ways that might produce a richer, more nuanced conceptual framework in which men's and women's practices, subjectivities, and bodies can be approached." ${ }^{99}$ Such an approach would undoubtedly move beyond the actions of those subjects socially categorized as men, while acknowledging men's agency within contexts shaped by power.

\section{AUTHORITY OF EXPERIENCE}

The emphasis on the behavior of particular men also highlights the importance of experience in the context of masculinity studies. Experience, in practice, often becomes the most authentic evidence on which to base claims to truth. Within masculinity studies, when the focus turns to ways of "doing" masculinity and to an analysis of the actions of men, "truth" is found through experiential claims. The paradigm suggested by turning toward the specific behavior of individuals is one in which the reality of patriarchy is attributable to the actions of certain bad apples. The focus on domination on a micro level renders the views of particular individuals the source of explanations. ${ }^{100}$ The problem with this is that "[experience] operates within an ideological construction that not only makes individuals the starting point of knowledge, but that also naturalizes categories such as man, woman, Black, white, heterosexual, or homosexual by treating them as given characteristics of individuals." 101 This tendency brushes aside issues of language, discourse, structure, and history, and instead focuses on how particular subjects experience the world. Rather than focusing on how particular subjectivities are constructed and how discourse precedes subjecthood, masculinity studies works generally from a more humanistic perspective that sees individuals who have experiences.

There appears to be a tension between the need for a local, contextualized approach to problems of gender oppression (which avoid buying into essentialist accounts of gender) and not overly relying on the evidence of experience; antiessentialism suggests going more micro while critiques of experience seem to suggest a more macro approach. The trend in masculinity studies has been to turn inward, to move from macro to micro, to be practical and focus on the actual behavior of men, rather than on big boring questions about discourse, theory, and language. But something gets lost in making this decision. There need not be any

\footnotetext{
Collier, supra note 2, at 473.

100 See Tracy E. Higgins, Anti-Essentialism, Relativism, and Human Rights, 19 Harv. WOMEN's L.J. (1996).

101 Joan W. Scott, The Evidence of Experience, 17 CritiCal InQuiry 773 (1991).
} 
grand theory that suddenly makes masculinity comprehensible. In fact, focusing on individual experiences is partly done because of a desire for tangible solutions, to reduce harm and eliminate suffering, to make the world a tangibly more just place. The implication is not to throw out experience - as we are cautioned by Scott, "[e] xperience is not a word we can do without, although, given its usage to essentialize identity and reify the subject, it is tempting to abandon it altogether,"102_-but simply not to rely on it as something apolitical and devoid of interpretation.

In the context of Ricci, we see how the experiences of the firefighters are constructed as the foundation of the truth. The categories within which the firefighters built their reality — e.g., white, Black, male, female — are made to appear ahistorical, and thus devoid of interpretation. The subjects, though, have been conceived within patriarchal and white supremacist social relations; the visions of the firefighters are structured through particular discourses and histories, and the experiences are not pre-discursive, but rather formed in discourse. The question, in this case, is not one of choosing between two alternative perspectives (white vs. Black; man vs. woman), but rather about questioning the structures that formed the subjects.

One of the insights from Janet Helms, the expert witness in Ricci, was that subjects are formed within existing social (e.g., racist and patriarchal) relations. It is not only that there are two contrasting perspectives that are equally true. That paradigm is palatable to the law, it adheres to the conventional narrative of history that new evidence is discovered that changes existing interpretations; the constant being that the experiences themselves are occurring to subjects and not that the subject are constituted by the experience. The insight of Helms is not palatable to the law, and, thus, her testimony was considered beyond the scope of the case and not taken seriously by either the majority opinion or the dissent. But the insight is an important one because it reorients the focus from the question of choosing between two contrasting experiences to that of the naturalness of the categories that structure the experiences themselves.

When experience is viewed as the foundation of truth, then we risk missing the fact that experience is both always already an interpretation and something that needs interpreting. The subject is constituted through the experience, as opposed to subjects simply having experiences. In practice, however, the law does determine which experiences to privilege and which perspective to adopt. In doing so, the fact that subjects are formed within patriarchal relations continues to play a role. In the example of Judge Kavanaugh's confirmation hearing, patriarchy rendered Dr. Ford's experience an interpretation while Judge Kavanaugh's was something to be interpreted.

Experience should not serve as a stand-in for an analysis of the production of knowledge. Thinking within the terms dictated by experience simply reproduces the categories of analysis without any critical turn, which, in the context of masculinity studies, is vital considering the validity, usefulness, and effect of the category, is what is being interrogated. Thinking about structural problems, the discursive construction of subjects, and of the need to think beyond and in different terms than sexual differences allow, is a daunting task without tangible near-term goals. Indeed, making the decisions to not pursue these questions, or rather to

$102 \quad$ Id. at 797. 
emphasize the others, is making a political decision; a decision that claims, rightly or wrongly, that the overarching political structure within which we live is capable of accommodating the changes that are sought.

\section{Political Nature of Sexual Difference}

Finally, the political nature of this emancipatory project is also present when one looks at the manner in which masculinity studies tends to think about subjectivity. The existence of a pre-existing subject buys into the humanist conception of each individual containing some sort of essence, and thus, potentially, being worthy of certain rights. Masculinity studies, therefore, by foregrounding a pre-discursive subject and describing its project as emancipatory, is implicitly buying into the politics of liberal humanism. It becomes difficult to suggest a radical politics or agenda within a discipline defined by those parameters. Masculinity studies is, essentially, a humanist project, striving for freedom and equality through rights and law, but it need not be. The focus can turn back to the political implications of thinking about sexual difference as naturalistic and inevitable, it can focus on the implications of thinking about masculinity studies as an emancipatory project focused on retrieving a pre-patriarchal space, it can stop exclusively focusing on the actions of individual men and recognize how experience is not the sole key to knowledge.

When thinking about and studying masculinity there is a fear that, as a culture, we will fall into silly stereotypes, that we will accept "frat boy" behavior out of young men, that we will propagate outdated ideas about what it means to be a man and about the rituals that "make boys men," that we will contribute to the seemingly endless perpetuation of patriarchy. But these should not be the only concerns. There are equally important questions about masculinity regarding more than just falling into stereotypical and essentialized ideas about masculinity. No longer does the major challenge - although it remains part of the challenge - only entail suggesting that masculinity comes in different shapes and sizes and that there is more than one way to be a man. It is no longer enough for critiques of masculinity to problematize sex roles and power imbalances, to highlight experiences of injustice, and to offer easy solutions that provide superficial critiques of patriarchy resorting back to an imaginary origin where equality was ubiquitous. Masculinity studies is in danger of turning clinical to avoid the uncertainty and agnosticism pivotal to an honest study of masculinity. Masculinity and the law remain pieces in a neoliberal puzzle that not only continues to re-articulate patriarchal relations in new ways, but falsely promises an illusory cohesiveness and an emancipation that is both inapt and misdirected. 